\title{
Cleaning up the EPA's act
}

\author{
On 12 March 2008, the US Environmental Protection Agency (EPA) released its latest standards for ozone emission, \\ along with recommendations on how to update the Clean Air Act. This was followed by public outcry from medical \\ associations, nonprofit organizations and media outlets.
}

$\mathbf{T}$ he Clean Air Act (CAA) is a piece of federal legislation, originally passed in 1963, aimed to support research and address concerns about air pollution. In 1970, in response to growing public concern, a new CAA was introduced to regulate air emissions, and this led to the creation of the EPA, a federal agency responsible for establishing emission standards for six air pollutants: ozone, particulate matter, carbon monoxide, sulfur oxides, nitrogen oxides and lead. The CAA was extensively revised in 1990, broadening the EPA's authority to implement and enforce the emission limits that it establishes. The standards must be reviewed every 5 years, to ensure that they reflect the latest scientific evidence. A recent Supreme Court decision ruled that the EPA has to regulate carbon dioxide and other greenhouse gas emissions, despite the agency's argument that these are not pollutants.

To develop these regulations, the EPA relies on science. According to its website (http://www.epa.gov), "sound science provides the foundation for credible environmental decision-making and is one of EPA's guiding principles to fulfill its mission to protect human health and the environment". The agency conducts research on environmental science in several of its own laboratories and research centers, and also provides grants and fellowships to support research in other institutions. An independent science advisory board provides advice for the regulations put forth by the EPA, whose administrator is appointed by the president of the United States.

The EPA's intent is laudable, and in principle the system should work well: the public health must certainly be among the highest priorities to the federal government, and decisions are taken on the basis of solid scientific evidence. But are these two premises real? The EPA's latest actions seem to suggest otherwise.

Ozone is found naturally in the Earth's atmosphere. Whereas stratospheric ozone has a role in filtering UV radiation from the sun, ground-level ozone is considered a pollutant by the World Health Organization. Ozone is not emitted directly into the air but is produced by the reaction between compounds emitted by industry, power plants and motor vehicles. Ozone has a distinct smell, and people can detect levels as low as 0.01 parts per million (p.p.m.). Exposure to higher concentrations is harmful to the respiratory system, with the elderly population, children and asthma patients more susceptible to its hazardous effects.

The EPA issues two different limit values, the so-called primary standard (to protect public health) and secondary standard (to protect public welfare, that is, the environment). The 2008 primary standard issued now by the EPA's administrator for ozone is 0.075 p.p.m. (maximum 8-h concentration). This is lower than the previous limit of 0.08 p.p.m. established in 1997, and the EPA has patted itself on the back for the "most stringent standard ever for ozone" in its news release. But the new limit falls short of the scientific advisory committee's recommendation of less than 0.070 p.p.m. In addition, the committee had recommended a secondary standard (in this case to protect crops and natural ecosystems, as ozone is also harmful to plants) different from and stricter than the primary standard, a proposal ignored by the EPA's administrator.

According to the CAA, the EPA should consider solely public health when setting air-quality standards, and not the economic costs of implementing them. This is a crucial legal point to protect the EPA's decisions from special interests. The constitutionality of this interpretation was upheld by the Supreme Court in 2001, when the EPA's 1997 air standards were challenged by the American Trucking Associations, the US Chamber of Commerce and other state and business groups.

And this was the second reason for protest against the EPA: among the proposed changes to the CAA announced by the agency's administrator was that "costs, risk trade-offs and feasibility" should be considered when determining air-quality standards (it should be noted that it is unlikely that such changes would be approved by the US Congress' Democrat majority).

Now, costs and benefits are always considered when making any kind of decision. But when it comes to determining what is harmful or acceptable, the core meaning of the EPA's standards, it just doesn't make any sense. If ' $X$ ' p.p.m. ozone is toxic, that's a fact, no matter how high the costs of reducing emissions might be.

On the other hand, how the EPA chooses to enforce its standards is another issue altogether. Emission standards can be implemented gradually, to lessen local economic impact. Another point to consider is that market forces and technology development will eventually find a way to lower the costs of reducing emissions, under the pressure exerted by the legislation. In other words, the terms and the value of the bill to be footed can be variable. But the levels set and enforced by the EPA to protect public and environmental health should be based on scientific evidence, and must not be negotiable. 